\title{
Protective Effect of Gemini Surfactant on Secondary Structural Change of Bovine Serum Albumin in Thermal Denaturation up to $130^{\circ} \mathrm{C}$
}

\author{
Yoshiko Moriyama, Yuu Tanizaki and Kunio Takeda* \\ Department of Applied Chemistry and Biotechnology, Okayama University of Science (1-1 Ridai-cho, Kita-ku, Okayama 700-0005, JAPAN)
}

\begin{abstract}
The effect of gemini surfactant, sodium dilauramidoglutamide lysine (DLGL), on the secondary structure of bovine serum albumin (BSA) was examined at $25^{\circ} \mathrm{C}$ and at high temperatures up to $130^{\circ} \mathrm{C}$. The helicity $(66 \%)$ of the protein decreased to $53 \%$ in the DLGL solution at $25^{\circ} \mathrm{C}$ and it also decreased to $16 \%$ with rise of temperature. Although approximately half of the original helical structures were destroyed upon heating up to $75^{\circ} \mathrm{C}$, most of the structures were maximally protected in the coexistence of $0.30 \mathrm{mM}$ DLGL at $75^{\circ} \mathrm{C}$ (the protein concentration was $0.010 \mathrm{mM}$ ). At temperatures below $75^{\circ} \mathrm{C}$, the protected helicity became maximal at such low DLGL concentrations. In the thermal denaturations above $80^{\circ} \mathrm{C}$, the protective effect did not appear at low DLGL concentrations, but monotonously enlarged with the surfactant concentration. On the other hand, upon cooling to $25^{\circ} \mathrm{C}$ after the thermal denaturations below $75^{\circ} \mathrm{C}$, the helicity was maximally recovered to about $60 \%$ in the presence of DLGL below $0.30 \mathrm{mM}$. Upon cooling to $25^{\circ} \mathrm{C}$ from high temperatures above $85^{\circ} \mathrm{C}$, the recovered helicity gradually increased with the surfactant concentration. The present novel effect, especially observed at low DLGL concentrations, might be fulfilled by the monomer ions of the gemini surfactant, since actual binding numbers of DLGL onto BSA are necessarily smaller than the mixing ratios around $30 \mathrm{~mol} / \mathrm{mol}$.
\end{abstract}

Key words: circular dichroism, gemini surfactant, amphiphilic material, protein structure, protection of protein structure

\section{INTRODUCTION}

Recently, attention has been paid to gemini-type surfactants with plural hydrophobic and hydrophilic groups. Various solution properties of the gemini-type surfactants have been studied so far focusing on the valence of hydrophilic group, chain length of hydrophobic group, and the nature and length of spacer ${ }^{1-10)}$. Generally, the gemini surfactants are known to be superior to ordinal single-chain surfactants in better wetting properties, greater surface activities (more efficiency to reduce surface and interfacial tension), and so on. Now, the gemini surfactants have been used also for cosmetic products. In spite of such interest and importance, the effects of gemini surfactants on the protein structures have not been investigated yet. In the present work, sodium dilauramidoglutamide lysine (DLGL) is adopted as a gemini surfactant. The hydrophilic moiety of this surfactant has two derivatives of amino acid, glutamic acid, connected by a spacer of another amino acid, lysine, as shown in Fig. 1. Since sur- factants derived from amino acids are mild and biodegradable, they are also widely used for cosmetic and toiletry products ${ }^{11}$. It is very interesting to know how a protein structure is influenced by these surfactants derived from amino acids.

On the other hand, many studies of interactions of proteins with ordinal ionic single-chain surfactants have been carried out for more than half a century ${ }^{12-15)}$. In these studies, bovine serum albumin (BSA) has been most frequently adopted as a protein ${ }^{14,15}$. It should be noted that the interactions has been investigated so far on the two component system of only protein and surfactant, that is, a target protein in the interactions has not been simultaneously affected by any other factor except for the coexisting surfactant. In the present study, the secondary structural change of BSA in the interaction with DLGL has been examined not only under ordinal condition but also under heat treatments at high temperatures up to $130^{\circ} \mathrm{C}$. In the latter case, the protein is necessarily affected by the thermal denatura-

${ }^{*}$ Correspondence to: Kunio Takeda, Department of Applied Chemistry and Biotechnology, Okayama University of Science, 1-1 Ridai-cho, Kita-ku, Okayama 700-0005, JAPAN

E-mail address: takeda@dac.ous.ac.jp

Accepted July 15, 2009 (received for review June 5, 2009)

Journal of Oleo Science ISSN 1345-8957 print / ISSN 1347-3352 online

http://www.jstage.jst.go.jp/browse/jos/ 


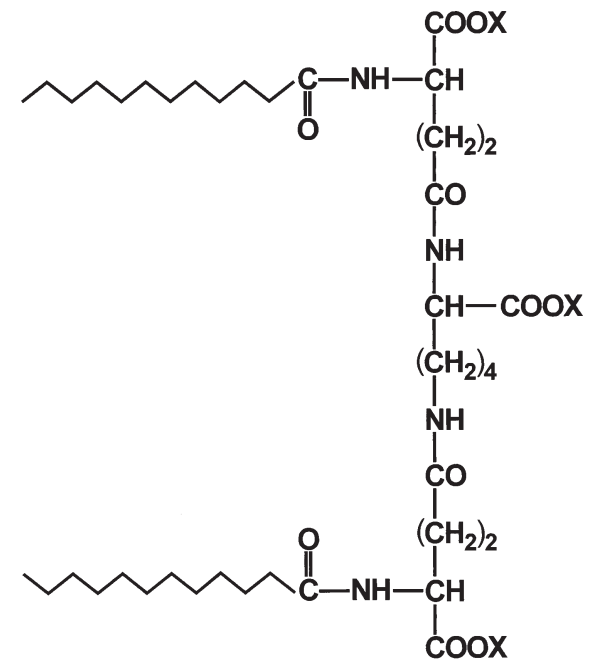

(X: Na)

Fig. 1 Chemical Structure of DLGL.

tion simultaneously with the additive effect of the surfactant. The results show that the protein structure can be protected in the thermal denaturation below $75^{\circ} \mathrm{C}$ in the coexistence of a small amount of DLGL. The effect of the gemini surfactant, DLGL, will be compared with that of a typical anionic single-chain surfactant, sodium dodecyl sulfate (SDS), which we have more recently reported ${ }^{16,17}$.

\section{EXPERIMENTAL}

BSA (A1900) was purchased from Sigma Chemical Co. ${ }^{16,17}$. DLGL was obtained from Asahi Kasei Chemicals Co. A sodium phosphate buffer of $\mathrm{pH} 7.0$ and ionic strength $0.014^{18-22)}$ was exclusively used to prepare each solution. The concentration of DLGL necessary to reduce the surface tension of the solvent by $20 \mathrm{mN} / \mathrm{m}$ (this concentration is often called as $\mathrm{C}_{20}$ ) was $<0.1 \mathrm{mM}$ in the present buffer. The surface tension of DLGL solution had a minimum around $1.2 \mathrm{mM}$, probably being close to the CMC in the buffer. The concentration of BSA was determined spectrophotometrically using $\varepsilon_{280}{ }^{23)}=4.4 \times 10^{4} \mathrm{M}^{-1} \mathrm{~cm}^{-1}$. The final protein concentration was adjusted to $10 \mu \mathrm{M}$.

CD measurements were carried out with a Jasco J-720 spectropolarimeter using a $1.0 \mathrm{~mm}$ path length cell at various temperatures up to $130^{\circ} \mathrm{C}$. We used a special high temperature cell holder system ${ }^{17}$ ordered from Japan Spectroscopic Corporation to heat an aqueous solution up to a temperature higher than $100^{\circ} \mathrm{C}$. A real temperature of the solution in the cell was determined with a thermocouple detector. The CD spectrum was measured after keeping the protein solution at a desired temperature for $30 \mathrm{~min}$. When the temperature was changed during the experiments or when the protein solution was kept at a certain temperature for thermal equilibrium, the cell containing the protein solution was protected from the ultraviolet beam. This is because the irradiation of ultraviolet light disrupts the structure of protein ${ }^{24,25)}$. The helicity (content of $\alpha$-helical structure) was estimated by the curve-fitting method of the $\mathrm{CD}$ spectrum, using the reference spectra as determined by Chen et al. ${ }^{26)}$. The simulation ${ }^{16,17,19-22)}$ was carried out in the wavelength region $200-240 \mathrm{~nm}$ at $1-\mathrm{nm}$ intervals.

\section{RESULTS AND DISCUSSION}

In the denaturation induced by ionic surfactants such as SDS, the helical structure is partially formed in nonhelical proteins and proteins with lower helicity, whereas it is disrupted in proteins with higher helicity ${ }^{14 a, 19-22)}$. BSA belongs to the latter. The helicity of BSA has been estimated to be $66 \%{ }^{14 a, 19}$. The helicity of $66 \%$ indicates that the helical structures are formed at 385 amino acid residues in the total residues, $583^{27}$, of BSA molecule. This helicity decreases to about $50 \%$ in the solutions of ionic surfactant such as SDS at $25^{\circ} \mathrm{C}^{14 a, 19)}$. This means that the helical structures at more than 90 residues of the protein are disrupted in the surfactant solutions.

\subsection{Structural change of BSA by DLGL at $25^{\circ} \mathrm{C}$}

The secondary structural change of BSA in the solution of a gemini surfactant was probably first examined in the present study. The change of helicity at $25^{\circ} \mathrm{C}$ is shown in Fig. 2 as a function of DLGL concentration. The helicity decreased with an increase of the surfactant concentration in the $\mathrm{mM}$ order range. Although the disrupted extent of the helical structure is slightly smaller than that in the

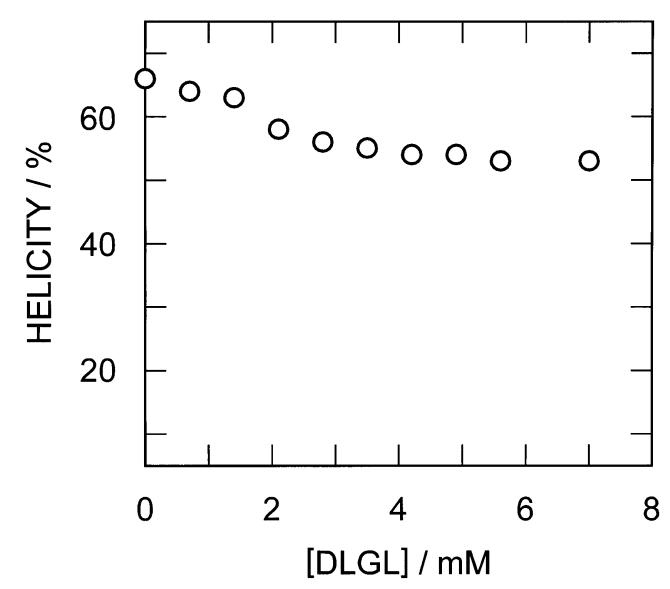

Fig. 2 Dependence of BSA Helicity on the DLGL Concentration at $25^{\circ} \mathrm{C}$.

The scale of vertical axis was identical with those in Figs. 3 and 4 to compare with them. 
SDS solution at $25^{\circ} \mathrm{C}^{14 a, 19)}$, this surfactant appears likely to be not so mild for a protein structure. Furthermore, the structure of BSA was disrupted at lower concentrations of DLGL compared with SDS ${ }^{14 a, 19)}$ in the same buffer, suggesting more functional effect of this surfactant with plural hydrophobic and hydrophilic groups, as mentioned below in the comparison with SDS.

\subsection{Effect of DLGL on structural change of BSA in thermal denaturation}

We have recently investigated the secondary structural change of BSA in the thermal denaturation up to $130^{\circ} \mathrm{C}^{17}$. The helicity of BSA begins to decrease beyond $30^{\circ} \mathrm{C}$ and sharply decreases between 50 and $100^{\circ} \mathrm{C}$. The helicity is $22 \%$ at $100^{\circ} \mathrm{C}$ and $16 \%$ at $130^{\circ} \mathrm{C}$. Most of the thermal disruption of helical structures occurs in the temperature range up to $100^{\circ} \mathrm{C}^{17}$. The helicity of $16 \%$ indicates that most of the helical structures are disrupted at $130^{\circ} \mathrm{C}$, but helical moieties, consisting of 93 amino acid residues in calculation (583 total residues $\times 0.16$ ), are still maintained even at this temperature. The reversibility of the protein structure is lost upon the descent of temperature after heating beyond $50^{\circ} \mathrm{C}$. Upon raising temperature beyond $50^{\circ} \mathrm{C}$, the higher the denaturation temperature is, the lower the recovered helicity is ${ }^{17)}$.

The main purpose of this study is to examine the effect of DLGL on the structural change of BSA in such a thermal denaturation. Therefore, the BSA solution containing DLGL of various concentrations was heated in temperature range up to $130^{\circ} \mathrm{C}$. Figure 3 shows the helicity changes of BSA in the DLGL solutions at several temperatures up to $130^{\circ} \mathrm{C}$. Some members of the series have been omitted for clarity.

Three trends of helicity change were observed. One was observed below $50^{\circ} \mathrm{C}$. As can be seen in this figure, the decreasing profile of the helicity with DLGL concentration at $50^{\circ} \mathrm{C}$ was similar to that at $25^{\circ} \mathrm{C}$ without heating. This indicates that the DLGL denaturation of BSA is not so affected by temperature below $50^{\circ} \mathrm{C}$. Figure 3 shows the results at 70 and $75^{\circ} \mathrm{C}$ as typical examples of the second trend. The decrement of the helicity was restrained in the presence of DLGL of low concentrations. The decrement of helicity decreased with an increase of DLGL concentration in a limited low concentration range at 70 and $75^{\circ} \mathrm{C}$. Approximately $60 \%$ helicity was maintained at $0.15 \mathrm{mM}$ DLGL at $70^{\circ} \mathrm{C}$. More than $50 \%$ helicity was maintained at $0.30 \mathrm{mM}$ DLGL at $75^{\circ} \mathrm{C}$. A similar trend was also observed at 55 and $60^{\circ} \mathrm{C}$ (not shown). After these maximal protective effects were observed at temperatures between 55 and $75^{\circ} \mathrm{C}$, the protected helicities decreased with an increase in the DLGL concentration within a limited concentration range. Especially at 70 and $75^{\circ} \mathrm{C}$, this trend was distinct as can be seen in Fig. 3. The protected helicity clearly became minimal around $1.5 \mathrm{mM}$ DLGL and increased with further

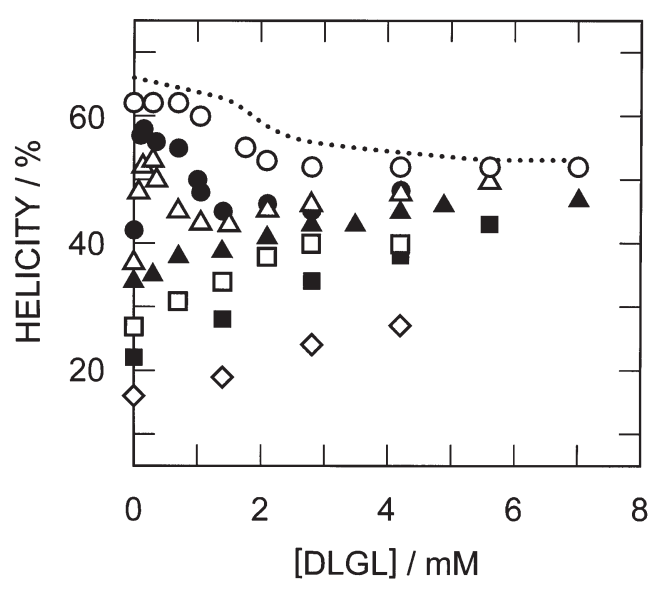

Fig. 3 Dependences of BSA Helicity on the DLGL Concentration at $50(\bigcirc), 70(\bigcirc), 75(\Delta), 80(\mathbf{\Delta})$, $90(\square), 100(\square)$, and $130^{\circ} \mathrm{C}(\diamond)$.

The dotted line indicates the helicity change of the protein at $25^{\circ} \mathrm{C}$.

increase in the surfactant concentration. The final helicities settled around 50\% at high DLGL concentrations. The third trend of helicity change was observed above $80^{\circ} \mathrm{C}$, where rather large amount of helical structures were thermally disrupted. The protected helicity gradually increased with an increase of DLGL concentration, that is, the decrement of the helicity by heating became more restrained as the surfactant concentration increased.

The present gemini surfactant, DLGL, shows the protective effect on the structure of BSA suffering the thermal denaturation. The extreme protective effect at lower DLGL concentrations appeared between 55 and $75^{\circ} \mathrm{C}$, whereas it did not above $80^{\circ} \mathrm{C}$. The present data indicate that the maximal protective effects between 55 and $75^{\circ} \mathrm{C}$ are fulfilled at the DLGL/BSA mixing molar ratios of 15 and $30 \mathrm{~mol} / \mathrm{mol}$ at 70 and $75^{\circ} \mathrm{C}$, respectively (BSA concentration is $0.01 \mathrm{mM}$ ). Actual binding numbers of DLGL ion to BSA are expected to be much smaller than these mixing ratios. There was a tendency that higher DLGL concentration was required to induce the maximal protective effect as the denaturation temperature was raised in this temperature range. After the protected helicities become maximal in this temperature range, they decrease and then increase with an increase in the DLGL concentration within a limited concentration range (Fig. 3). Minima of the protected helicities appear around $1.5-2 \mathrm{mM}$ DLGL at 70 and $75^{\circ} \mathrm{C}$ as seen in Fig. 3. Such a minimum of the protective effect is not observed in the case of SDS ${ }^{17}$. However, even a magnitude of the minimal protected helicity was appreciably larger than the helicities at these temperatures in the absence of DLGL. This indicates that the presence of DLGL brings about the protection of the protein structure to some degree at any surfactant concentration. 
The protective effect beyond $80^{\circ} \mathrm{C}$ gradually increased with an increase of DLGL concentration, as shown in Fig. 3. Interestingly, the helicity generally tended to approach around 50\% at high DLGL concentrations irrespective of temperatures between 25 and $100^{\circ} \mathrm{C}$. This suggests that the final BSA-DLGL complex (the surfactant-binding-saturated-complex), the secondary structure of which corresponds to about $50 \%$ helicity, is rather stable in the heat treatment in this temperature range. A similar tendency has been observed in the effect of SDS.

\subsection{Effect of DLGL on helicity recovery upon cooling}

In the present study, we also examined the effect of DLGL on the recovery of the helicity upon cooling to $25^{\circ} \mathrm{C}$ after the heat treatment. It is already known that the secondary structure of BSA completely recovers upon cooling from temperatures below $50^{\circ} \mathrm{C}$, but it does not above this temperature ${ }^{16,17}$. Figure 4 shows the helicities of BSA at various concentrations of DLGL upon cooling to $25^{\circ} \mathrm{C}$ after the heat treatment. Upon cooling to $25^{\circ} \mathrm{C}$ from $50^{\circ} \mathrm{C}$, the recovered helicity at each DLGL concentration was mostly the same as that adopted at $25^{\circ} \mathrm{C}$ before heating. Upon cooling to $25^{\circ} \mathrm{C}$ from temperatures between 55 and $75^{\circ} \mathrm{C}$, however, the recovered helicity became maximal at low DLGL concentrations. The protective effects of low DLGL concentrations were typically observed upon cooling to $25^{\circ} \mathrm{C}$ from 70 and $75^{\circ} \mathrm{C}$. They correspond to the same observations that the protective effects become maximal at low DLGL concentrations upon keeping high temperatures in this temperature range. Although the protective effects of low DLGL concentrations were not observed upon keeping temperature at $80^{\circ} \mathrm{C}$ in Fig. 3, the recovered helicity became maximal around $1.5 \mathrm{mM}$ DLGL upon cooling to $25^{\circ} \mathrm{C}$ from this temperature, as seen in Fig. 4. In this case, much amount of DLGL was required to induce the maximal recovery of helicity compared with $0.30 \mathrm{mM}$ required upon cooling from $75^{\circ} \mathrm{C}$. The temperature of $80^{\circ} \mathrm{C}$ appears to be some boundary in the interaction of BSA with DLGL. A similar boundary temperature has also been observed in the BSA-SDS interaction ${ }^{17)}$. The boundary temperature region slightly shifts toward higher temperature upon cooling to $25^{\circ} \mathrm{C}$ in the effects of both SDS and DLGL. This might be due to a decrease of binding number of each surfactant ion to BSA with rise of temperature in addition to the disruption of helical structures by heating. Upon cooling from temperatures below $80^{\circ} \mathrm{C}$, the recovered helicity became maximal at a particular DLGL concentration and decreased with an increase in the surfactant concentration down to a magnitude around 50\%. However, upon cooling from $90^{\circ} \mathrm{C}$, a maximum of the recovered helicity was not observed at low DLGL concentrations. When the solution was cooled to $25^{\circ} \mathrm{C}$ from temperatures above $90^{\circ} \mathrm{C}$, the recovered helicity gradually increased with an increase of DLGL concentration, but the final helicity became lower

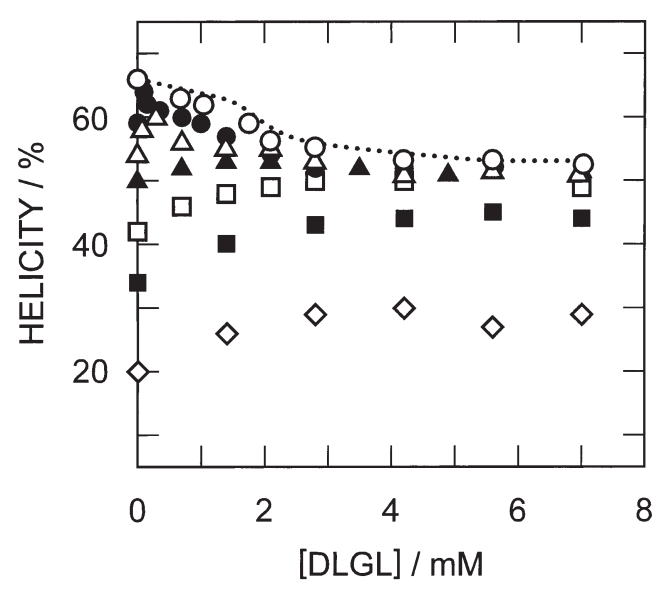

Fig. 4 Dependences of BSA Helicity on the DLGL Concentration upon Cooling to $25^{\circ} \mathrm{C}$ from $50(\bigcirc)$, $70(\bigcirc), 75(\Delta), 80(\boldsymbol{\Delta}), 90(\square), 100(\square)$, and $130^{\circ} \mathrm{C}(\diamond)$.

The dotted line indicates the helicity change of the protein at $25^{\circ} \mathrm{C}$ before heating.

than those upon cooling from temperatures below $80^{\circ} \mathrm{C}$, as shown in Fig. 4. Although the final recovery of helicity upon cooling from $90^{\circ} \mathrm{C}$ was still closed to those obtained by cooling from temperatures below $80^{\circ} \mathrm{C}$, it appreciably became lower for the cases of cooling from temperatures above $100^{\circ} \mathrm{C}$. Such low recoveries at high temperatures have also been observed in the effect of SDS on the BSA structure $^{17)}$. More than half of the helical structures of BSA are disrupted above $80^{\circ} \mathrm{C}^{17}$, and it seems that a damage above $80^{\circ} \mathrm{C}$ is too large-scaled to be reformed by the interaction with these surfactants. Upon suffering to such high temperatures, the bound DLGL ions appear to be rearranged on BSA, forming completely different complexes between them from those formed at lower temperatures.

\subsection{Comparison with SDS and feasible mechanism of inter- action}

The protection and the recovery of the helicity of BSA by the present DLGL with plural hydrophobic and hydrophilic groups are totally similar to those by $\operatorname{SDS}^{17}$. However, there are distinct differences between DLGL and SDS. These effects of DLGL appear in lower concentrations than those of SDS. The hydrophobicity of DLGL with two hydrophobic groups is an important factor to show a great surface activity: this surfactant has the characteristic concentration $\left(\mathrm{C}_{20}\right)$ below $0.1 \mathrm{mM}$ to reduce the surface tension of the solvent by $20 \mathrm{mN} / \mathrm{m}$ as stated in EXPERIMENTAL. Therefore, the CMC of DLGL is appreciably lower than that of SDS. This difference is essentially related to the fact that the binding of ionic surfactants to protein such as BSA generally proceeds in their free concentrations below the CMC. 
On the other hand, the maximal protective effect of low SDS concentrations appears until $85^{\circ} \mathrm{C}^{17)}$, whereas those of lower DLGL concentrations appears until $75^{\circ} \mathrm{C}$. Upon cooling to $25^{\circ} \mathrm{C}$, the maximal recovered helicity at lower SDS concentrations occurs until cooling from $90^{\circ} \mathrm{C}^{17)}$, whereas the maximal protective effect of lower DLGL concentrations does until cooling from $80^{\circ} \mathrm{C}$. These effects at low concentrations of SDS continue to be observed until slightly but appreciably higher temperatures compared with those of DLGL for both thermal denaturation and recovery. Related to this, we consider at present that, compared with the bulkiness of DLGL, the compactness of dodecyl sulfate ion with one hydrophobic group and one hydrophilic group appears to be effective to exhibit these effects up to higher temperatures. We have previously examined the binding isotherm to BSA of sodium bis(2-ethylhexyl) sulfosuccinate (AOT) with two hydrophobic groups and the secondary structural change of the protein by this surfactant under the same condition as the present work. ${ }^{28}$. The CMC of AOT is $2.5 \mathrm{mM}$ in the buffer. The helicity of BSA decreases at lower concentrations of AOT compared with SDS. The saturated binding amount of this surfactant to BSA is about $70 \mathrm{~mol} / \mathrm{mol}^{28)}$ as against about $200 \mathrm{~mol} / \mathrm{mol}$ of the corresponding amount of SDS determined under the same condition $^{14 a, 18)}$.Both the surfactants, DLGL and AOT, with plural hydrophobic groups are superior to SDS in the effect to disrupt the helical structures of BSA, but the former two surfactants are inferior to the latter in the binding amounts to the protein. Although there are not binding data at high temperatures, we speculate that dodecyl sulfate ions more strongly interact with the protein than the surfactants with plural hydrophobic groups at high temperatures.

The protein-surfactant interactions have extensively been studied so far, but the present study is probably the first try to examine the interaction of gemini surfactant with protein. Moreover, the present examination of BSA-DLGL interaction has been made for the protein, which is simultaneously affected by another factor, thermal denaturation, as well. The thermal denaturation is one of the characteristic properties of protein. It has been understood in a qualitative sense that an original protein structure is disrupted in the thermal denaturation alone. On the other hand, the structure of BSA is disrupted in the DLGL denaturation alone (Fig. 2). However, the effect of thermal denaturation is distinctly prevented by the coexistence of DLGL. Especially, it is noteworthy that the secondary structure of the protein mostly recovers to the original state (the original helicity in the strict sense) in the presence of a small amount of DLGL upon cooling to $25^{\circ} \mathrm{C}$ from temperatures below $75^{\circ} \mathrm{C}$. It is well discussed in the interactions of surfactant with protein or polymer that a surfactant exhibits a characteristic function by forming a micelle-like aggregate on a protein or polymer ${ }^{12-15)}$. In the present case, however, this novel effect might be fulfilled by the monomer ions of DLGL. This is because the maximal protective effect occurs at the mixing ratios of [DLGL] $/[\mathrm{BSA}]$ of 15 to 30 of at 70 and $75^{\circ} \mathrm{C}$ (Fig. 3) and the maximal recovery of the helicity appears at the mixing ratios of 10 to 30 upon cooling from 70 and $75^{\circ} \mathrm{C}$ (Fig. 4). These mixing ratios are calculated using the total concentrations of the surfactant below $0.3 \mathrm{mM}$ for the protein concentration of $10 \mu \mathrm{M}$. Similar prominent effects of surfactants on the structural changes of BSA and human serum albumin (HSA) have previously been observed also at much lower mixing ratios. For example, prominent protective effects occur on the BSA structure at the mixing ratios of $[\mathrm{SDS}] /[\mathrm{BSA}]$ below 6 at 50,60 , and $65^{\circ} \mathrm{C}^{16}$. At the mixing ratios of $[\mathrm{AOT}] /[\mathrm{HSA}]$ of 5 to 15 , similar effects have been observed on the HSA structure at $65^{\circ} \mathrm{C}^{28)}$. In addition, similar protection and recovery have been observed at the mixing ratios below $10 \mathrm{~mol} / \mathrm{mol}$ in urea denaturation ${ }^{29,30)}$ as well. It should be noted that actual binding numbers of surfactant ion to the protein are necessarily smaller than the mixing ratios of the surfactant concentration where these prominent effects are observed. Here, there is a possibility that small micelle-like aggregates of surfactants are formed at one or two sites on the protein molecule. However, in order to induce the aforementioned effects, such aggregates would be necessary to be formed on several particular sites on the protein molecule. Even around the mixing ratio of [DLGL]/[BSA] of 30 , the total surfactant concentration must be insufficient to form micelle-like aggregates separately on several particular sites of the protein molecule. Then, the present effects are considered to be fulfilled by the monomer ions of DLGL: the protein structure might be stabilized by a cross-linking function of the anionic surfactant ions between a group of nonpolar residues and a positively charged residue in the proteins. This concept, introduced by Markus et $a l^{31,32)}$, has be verified later by the following two facts. (1) The X-ray crystallographic study of lysozyme-SDS system has demonstrated that the hydrophobic chain of the surfactant contacts with particular hydrophobic residues and that the hydrophilic group of the same surfactant forms salt-bridges with charged residues $^{33}$. (2) The present protective effect of ionic surfactant on the protein structure is influenced by the hydrophobic chain length and a positive or negative charge of hydrophilic group of surfactant (a negative charge of the hydrophilic group is needed in this effect on BSA, since a cationic surfactant does not protect the protein structure at all) ${ }^{16)}$.

\section{CONCLUSION}

It is found that the gemini surfactant, DLGL, acts to pro- 
tect the BSA structure in a monomer state in a similar manner to an ordinal anionic surfactant, SDS. The effect of the surfactant on the secondary structure of BSA distinctly differs below and above a boundary temperature around $80^{\circ} \mathrm{C}$. Further studies on another protein are in progress and will be reported in due course. These phenomena have been overlooked in many studies of mixed systems of only surfactant and protein. Such a protective effect can be observed only in the interactions of surfactant with protein that is simultaneously influenced by another factor. These examinations might clarify characteristic properties of surfactant as well as protein. The present protective effect is due to both the hydrophobic nature and hydrophilic nature of the anionic surfactant ion used in this work. This information suggests a possibility that amphiphilic materials such as a phospholipid might act not only to form vesicles but also to affect structures and functions of proteins as characteristic and strong amphiphilic monomers.

\section{References}

1. Menger, F.M.; Littau, C.A. Gemini surfactants: A new class of self-assembling molecules. J. Am. Chem. Soc. 115, 10083-10090 (1993).

2. Song, L.D.; Rosen, M.J. Surface properties, micellization, and premicellar aggregation of gemini surfactants with rigid and flexible spacers. Langmuir 12, 1149-1153 (1996).

3. Rosen, M.J.; Mathias, J.H.; Davenport, L. Aberrant aggregation behavior in cationic gemini surfactants investigated by surface tension, interfacial tension, and fluorescence methods. Langmuir 15, 7340-7346 (1999).

4. Kunieda, H.; Masuda, N.; Tsubone, K. Comparison between phase behavior of anionic dimeric (gemini-type) and monomeric surfactants in water and water-oil. Langmuir 16, 6438-6444 (2000).

5a. Mathias, J.H.; Rosen, M.J.; Davenport, L. Fluorescence study of premicellar aggregation in cationic gemini surfactants. Langmuir 17, 6148-6154 (2001).

5b. Zana, R. Comments on fluorescence study of premicellar aggregation in cationic gemini surfactants. Langmuir 18, 7759-7760 (2002).

6. Zana, R. Alkanediyl- $\alpha, \omega$-bis(dimethylalkylammonium bromide) surfactants: 10 Behavior in aqueous solution at concentrations below the critical micellization concentration: an electrical conductivity study. J. Colloid Interface Sci. 246, 182-190 (2002).

7. Li, X.; Wettig, S.D.; Wang, C.; Foldvari, M.; Verrall, R.E. Synthesis and solution properties of gemini surfactants containing oleyl chains. Phys. Chem. Chem Phys. 7, 3172-3178 (2005).

8. Li, Y.; Li. P.; Wang, J.; Wang, Y.; Yan, H.; Thomas, R. K.
Odd/even effect in the chain length on the enthalpy of micellization of gemini surfactants in aqueous solution. Langmuir 21, 6703-6706 (2005).

9. Abe, M.; Tsubone, K.; Koike, T.; Tsuchiya, K.; Ohkubo, T.; Sakai, H. Polymeririzable cationic gemini surfactant. Langmuir 22, 8293-8297 (2006).

10. Jiang, Y.; Chen, H.; Cui, X-H.; Mao, S-Z.; Liu, M-L.; Luo, P-Y; Du, Y-R. H-NMR study on pre-micellization of quaternary ammonium gemini surfactants. Langmuir 24, 3118-3121 (2008).

11. Kaneko, D.; Olsson, U.; Sakamoto, K. Self-assembly in some N-lauroyl-L-glutamate/water systems. Langmuir 18, 4699-4703 (2002).

12. Steinhardt, J.; Reynolds, J.A. Multiple Equilibria in Proteins. Academic Press. New York. pp. 239-302 (1969).

13. Jones, M.N. Biological Interfaces. Elsevier. Amsterdam. pp.101-130 (1975).

14a. Takeda, K.; Moriyama, Y.; Hachiya, K. Interaction of protein with ionic surfactants. Part 1. Binding of surfactant to protein and protein fragments, and conformational changes induced by binding. in Encyclopedia of Surfactant and Colloid Science (Hubbard, A.T. ed.). Marcel Dekker. New York. pp. 2558-2574 (2002).

14b. Takeda, K.; Hachiya, K.; Moriyama, Y. Interaction of protein with ionic surfactants. Part 2. Kinetics of conformational change of protein induced by the binding of surfactant; Dynamics of protein-surfactant complexes; Interaction of protein with reverse micelles. in Encyclopedia of Surfactant and Colloid Science (Hubbard, A.T. ed.). Marcel Dekker. New York. pp.2575-2592 (2002).

15. Takeda, K.; Moriyama, Y. Comment on the misunderstanding of the BSA-SDS complex model: Concern about publications of an impractical model. J. Phys. Chem. B 111, 1244 (2007).

16. Moriyama, Y.; Kawasaka, Y.; Takeda, K. Protective effect of small amounts of sodium dodecyl sulfate on the helical structure of bovine serum albumin in the thermal denaturation. J. Colloid Interface Sci. 257, 41-46 (2003).

17. Moriyama, Y.; Watanabe, E.; Kobayashi, K.; Harano, H.; Inui, E.; Takeda, K. Secondary structural change of bovine serum albumin in the thermal denaturation up to $130^{\circ} \mathrm{C}$ and protective effect of sodium dodecyl sulfate on the change. J. Phys. Chem. B 112, 16585-16589 (2008).

18. Takeda, K.; Miura, M.; Takagi, T. Stepwise formation of complexes between sodium dodecyl sulfate and bovine serum albumin detected by measurements of electric conductivity, binding isotherm, circular dichroism. J. Colloid Interface Sci. 82, 38-44 (1981).

19. Takeda, K.; Shigeta, M.; Aoki, K. Secondary structures of bovine serum albumin in anionic and cationic sur- 
factant solutions. J. Colloid Interface Sci. 117, 120-126 (1987).

20. Takeda, K.; Sasa, K.; Nagao, M.; Batra, P.P. Biochim. Biophys. Acta 957, 340-344 (1988).

21. Takeda, K.; Sasa, K.; Kawamoto, K.; Wada, A.; Aoki, K. Secondary structures of disulfide bridge-cleaved bovine serum albumin in solutions of urea, guanidine hydrochloride, and sodium dodecyl sulfate. J. Colloid Interface Sci. 124, 284-289 (1988).

22. Takeda, K.; Wada, A.; Nishimura, T.; Ueki, T.; Aoki, K. Isolation of domain-sized fragments of bovine serum albumin by limited peptic digestion and their secondary structural changes in solutions of urea, guanidine hydrochloride, and sodium dodecyl sulfate. $J$. Colloid Interface Sci. 133, 497-504 (1989).

23. Sober, H.A.; Harte, R.A. ed. Handbook of Biochemistry (Selected Data for Molecular Biology) $2^{\text {nd }}$ edn. CRC Press. Cleveland. P. C-71 (1973).

24. Takeda, K.; Moriyama, Y. Unavoidable time-dependent ellipticity changes of proteins in the current CD measurements. J. Am. Chem. Soc. 113, 6700-6701 (1991).

25. Moriyama, Y.; Kakehi, T.; Takeda, K. Changes of $\alpha$-helical and $\beta$-structural conformations of polypeptides caused by the irradiation of xenon lamp in the current circular dichroism apparatus. Anal. Biochem. 219, 378-380 (1994).

26. Chen, Y.H.; Yang, J.T.; Chau, K.H. Determination of the helix and $\beta$ form of proteins in aqueous solution by circular dichroism. Biochemistry 13, 3350-3359 (1974).

27. Hirayama, K.; Akashi, S.; Furuya, M.; Fukuhara, K.
Rapid conformation and revision of the primary structure of bovine serum albumin by ESIMS and FRIT-FAB LC/MS. Biochem. Biophys. Res. Commun. 173, 639-646 (1990).

28. Takeda, K.; Harada,K.; Yamaguchi, K.; Moriyama, Y. Conformational changes of bovine serum albumin in an aqueous solution of sodium bis (2-ethylhexyl) sulfosuccinate and in the reverse micelle of the same surfactant. J. Colloid Interface Sci. 164, 382-386 (1994).

29. Moriyama, Y.; Sato, Y.; Takeda, K. Reformation of the helical structure of bovine serum albumin by the addition of small amounts of sodium dodecyl sulfate after the disruption of the structure by urea. J. Colloid Interface Sci. 117, 420-424 (1993).

30. Moriyama, Y.; Takeda, K. Reformation of the helical structure of human serum albumin by the addition of small amounts of sodium dodecyl sulfate after the disruption of the structure by urea. A comparison with bovine serum albumin. Langmuir 15, 2003-2008 (1999).

31. Markus, G.; Karush, F. Structural effects of the interaction of human serum albumin with sodium dodecyl sulfate. J. Am. Chem. Soc. 79, 3264-3269 (1957).

32. Markus, G.; Love, R.L.; Wissler, F.C. Mechanism of protection by anionic detergents against denaturation of serum albumin. J. Biol. Chem. 239, 3687-3693 (1964).

33. Yonath, A.; Prodjarny, A.; Honig, B.; Sielecki, A.; Traub, W. Crystallographic studies of protein denaturation and renaturation. 2 Sodium dodecyl sulfate induced structural changes in triclinic lysozyme. Biochemistry 16, 1418-1424 (1977). 